\title{
'Ökonomischer Patriotismus' in Zeiten regionaler und internationaler Integration
}

Zur Problematik staatlicher Aufsicht über grenzüberschreitende Unternehmensübernahmen

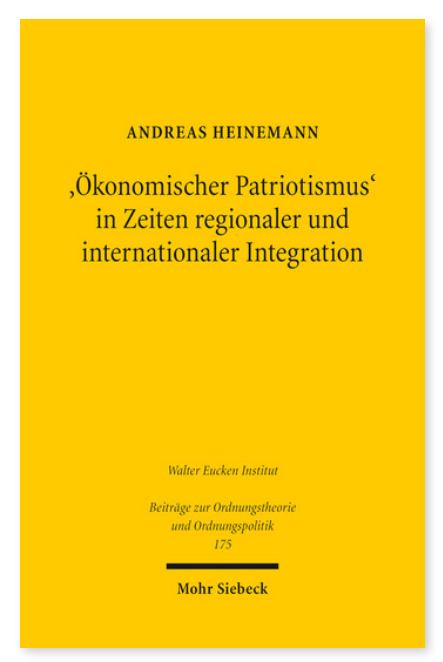

2011. 122 Seiten. BOrd 175

ISBN 978-3-16-151747-1

DOI 10.1628/978-3-16-151747-1

eBook PDF $34,00 €$

ISBN 978-3-16-150786-1

Broschur $34,00 €$
Immer mehr Staaten gehen dazu über, die Übernahme heimischer Unternehmen durch ausländische Investoren einer besonderen Kontrolle zu unterstellen. Dies erscheint legitim, solange die staatliche Aufsicht den Schutz der nationalen Sicherheit bezweckt. Nicht selten gehen Regierungseingriffe aber hierüber hinaus und schreiben sich in einen Gesamtzusammenhang ein, den man in Frankreich als »Ökonomischen Patriotismus « bezeichnet hat. Staatliche Eingriffe müssen die rechtlichen Vorgaben respektieren, die im Recht der Europäischen Union sehr viel strenger als im Internationalen Wirtschaftsrecht sind. Die entscheidende rechtspolitische Frage ist wirtschaftlicher Natur: Befördert es das Wohlergehen eines Landes, wenn man inländische Unternehmen vor Übernahmen aus dem Ausland schützt? Erhebliche Zweifel sind angebracht. Die unbestreitbaren Probleme, wie z.B. mangelnde Reziprozität oder Bedenken gegenüber ausländischen Staatsfonds, sollten durch Verbesserungen des internationalen Regelwerks kuriert werden.

Andreas Heinemann Geboren 1962; Studium der Rechts- und Wirtschaftswissenschaften; 1995 Promotion; 2000 Habilitation; 2001-07 Lehrstuhl für deutsches Recht an der Universität Lausanne; seit 2007 Lehrstuhl für Handels-, Wirtschafts- und Europarecht an der Universität Zürich; Mitglied der Schweizer Wettbewerbskommission.

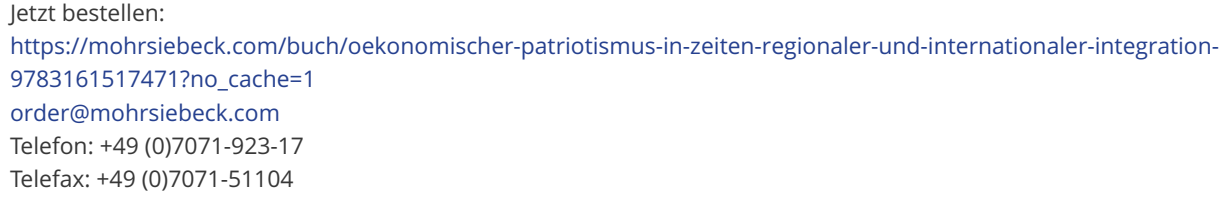

